\title{
ENSINO MÉDIO E PROJETO DE VIDA: POSSIBILIDADES E DESAFIOS
}

\author{
HIGH SHOOL AND LIFE PROJECT: POSSIBILITIES AND \\ CHALLENGES
}

\author{
Kaliana Silva Santos ${ }^{1}$ \\ Simone Braz Ferreira Gontijo ${ }^{2}$
}

\begin{abstract}
Resumo: 0 presente artigo propõe-se a analisar a temática Projeto de vida como componente curricular obrigatório na Base Nacional Comum Curricular (BNCC) do Ensino Médio a fim de analisar possibilidades de inserção dessa temática nesse nível de ensino. 0 trabalho consiste numa revisão bibliográfica realizada em bases de dados, em especial Scielo e Redalyc, utilizando-se como filtro as palavras-chave: projeto de vida, juventude e ensino médio. As leituras demonstram que para se obter sucesso na construção de uma proposta pedagógica que considere o Projeto de vida como componente curricular deve-se levar em conta várias vertentes, dentre elas, destaca-se: não se resumir a uma escolha profissional devendo ampliarse aos múltiplos espectros da vida do sujeito em questão; primar pelo fomento ao autoconhecimento, a relação com o outro e com a sociedade, o planejamento e a preparação para o mundo do trabalho. Essas competências deverão ser construídas ao longo dos três anos do Ensino Médio a partir de atividades mediadas pelos princípios da aprendizagem dialógica. Conclui-se que, apesar dos autores considerarem complexo trabalhar o projeto de vida devido as inúmeras variáveis que esse tema apresenta, é fundamental fazê-lo na escola, lugar onde a integralidade do sujeito está em formação.
\end{abstract}

Palavras-chave: projeto de vida, juventude, ensino médio, BNCC, Reforma do ensino médio.

\begin{abstract}
This article proposes to analyze the thematic Life project as a mandatory curricular component in the National Curriculum Common Base (BNCC) of High School in order to present possibilities of insertion of this thematic in this level of education and consists of a bibliographic review. The readings demonstrate that in order to be successful in the construction of a life project, several aspects must be considered, among which it is emphasized that it should not be limited to a professional choice, instead should expand the multiple spectra of the subject's life in question; it must excel in promoting self-knowledge, the relationship with others and with society, the planning and preparation for the world of work. These competences should be built over the three years of high school based on activities mediated by the principles of dialogical learning. It is concluded that although the authors consider

it complex to work on the life project due to the numerous variables that this theme

presents, it is fundamental to do it at school, a place where the integrality of the subject is in formation.
\end{abstract}

Keywords: life project, youth, high school, BNCC, high school reform.

\footnotetext{
1 Mestranda em Educação Profissional e Tecnológica pelo ProfEPT/IFB campus Brasília. Docente no município de Itabuna - BA. Lattes: http://lattes.cnpq.br/4466265524259925

2 Professora do Instituto Federal de Brasília, atuando como docente do curso de mestrado profissional em Educação Profissional e Tecnológica e do curso de Letras/ Espanhol do campus Ceilândia. Possui graduação em Pedagogia pela Universidade Católica de Brasília (1994), Especialização em Política e Estratégia (ADESG/UnB), Administração da educação (UnB), Educação a Distância (UnB), Mestrado (2001) e Doutorado em Educação pela Universidade de Brasília (2014). Lattes: http://lattes.cnpq.br/6448190142283114 Orcid: https://orcid.org/0000-0002-8245-3841
} 


\section{Introdução}

Não saber que carreira seguir, estar em constante autoconhecimento, novas descobertas do mundo interior e exterior são dilemas recorrentes na adolescência. Saindo do ensino fundamental e ingressando no ensino médio os jovens começam a projetar o futuro e considerar as possibilidades a sua volta. As conversas com amigos, a pressão dos pais, a necessidade de ter sua própria renda, a vontade de querer conquistar o mundo começa a tomar corpo nessa fase.

Para Dayrell (2003) a visão de condição transitória do mundo jovem para o mundo adulto, do "vir a ser" é negativa, pois nega-se o presente vivido, perde-se a totalidade da existência juvenil, uma vez vista como fase passageira, efêmera e com foco exclusivamente no futuro.

Essa concepção está presente na escola onde em nome do "vir a ser" do estudante, assegurado após a formatura e pelos possíveis projetos de futuro, tende-se a negar o presente vivido do jovem como espaço válido de formação, assim como as questões existenciais, bem mais presentes (DAYRELL, 2003, p. 41). É preciso estar atento à problemática jovem para evitar o senso comum, preconceitos arraigados na sociedade, de forma a não limitar as expectativas desses sujeitos.

Nesse sentido, diante de um mundo imprevisível, instável e repleto de oportunidades, ter metas de vida pode ser uma maneira de guiar as escolhas de cada indivíduo, buscando significados que são duradouros e capazes de transcender interesses imediatos e individualistas (ARANTES; KLEIN, 2016). É nesse contexto que o projeto de vida se configura como um grande aliado, um caminho duradouro, sólido e contínuo frente aos inúmeros atalhos que a vida hodierna oferece. A saída da casa dos pais, o casamento, a entrada para o mercado de trabalho eram fatos que, no início do século XX, tinham data previsível para acontecer e os jovens tomavam para si as responsabilidades de adulto. Atualmente, como nada ou quase nada está prédeterminado, não há mais o caráter linear dos acontecimentos e a certeza que se tem é a incerteza do futuro. Aliás, o adiamento da saída das casas dos pais vem se tornando frequente nas classes economicamente favorecidas.

A Base Nacional Comum Curricular (BNCC) do Ensino Médio de 2018 visa a construção de um currículo baseado na educação integral e com o desenvolvimento pleno do estudante. Entre as dez competências listadas no documento encontra-se o projeto de vida como um dos elementos para construção da formação integral. A BNCC como documento norteador dos currículos escolares busca, por meio dessa competência, reiterar o foco no estudante, no protagonismo discente e no seu projeto de vida.

Com base nessas reflexões esse artigo tem objetivo analisar, a partir da bibliografia disponível, a temática Projeto de vida como componente curricular obrigatório na Base Nacional Comum Curricular (BNCC) do Ensino Médio e as possibilidades de inserção dessa temática nesse nível de ensino. A metodologia utilizada foi a pesquisa 
bibliográfica realizada em bases de dados, em especial Scielo e Redalyc, utilizando-se como filtro as palavras-chave: projeto de vida, juventude e ensino médio.

\section{Juventude e Projeto de vida}

Juventude e adolescência são categorias complexas, compreendidas como fenômenos históricos, políticos e culturais, no ocidente, nos remete à Europa, entre o final do século XIX e o início do século XX, quando a "adolescência" torna-se objeto de investigação das ciências médicas e psicopedagógicas, no auge da ciência positivista (SILVA; LOPES, 2009, p. 89).

Neste trabalho, ora usamos o termo adolescente, ora juventude para indicar os sujeitos no referencial teórico. A diferença nos termos é vista mais centrada no processo de conquista de direitos, os quais os jovens ainda têm menos acesso que os adolescentes. Portanto, quando a pesquisa a qual nos referimos usar literalmente o termo adolescente esse será utilizado no trabalho. Porém, nos utilizaremos em outras situações, os termos jovens, juventude e juventudes como "forma de dar visibilidade às questões, demandas e necessidades dos jovens, entendidos de uma forma mais ampla" (DAYRELL; CARRANO, 2014, p. 109).

Os costumes, comportamentos, valores vão se modificando a cada geração, a cada década e com isso a representação social reestrutura-se paulatinamente assim como os sujeitos inseridos no contexto sócio-histórico-cultural. Como destacado por Mannheim (1968), o grau de mudanças em uma sociedade interfere no significado atribuído aos jovens e ao papel que a educação deverá desempenhar. Ter consciência dessas mudanças é importante para que a escola, os professores, pais e a sociedade saibam conduzir esse adolescente.

Com a modernidade presente no cotidiano das pessoas, essa aquisição de papeis e a representação social ganham um novo mundo - o espaço virtual. As redes sociais, smartphones, aplicativos, selfies fazem parte da geração que traz um espírito empreendedor, entende o novo, capta e transforma tudo. A geração Z é a definição sociológica para pessoas nascidas entre os anos de 1990 a 2010. São nativos digitais, conectados, móveis, não viram o mundo sem internet e tem como características serem hiper cognitivos, capazes de viverem múltiplas realidades, tanto presenciais quanto digitais.

Segundo Homem (2019, p. 98) "os perfis virtuais também demandam opiniões, fotos, posicionamentos constantes, produzimos realidades imaginárias, onde inventamos um personagem para nós mesmos. E em alguns casos ele se torna o protagonista." Recriando rotineiramente uma realidade digital cabe a seguinte reflexão: posto, logo existo?

posts, likes e compartilhamentos têm mudado a forma como construímos nossos ideais de existência - aquilo que queremos ser, construir e vivenciar. Até recentemente, essa invenção de nós mesmos se dava a partir de experiências vividas e de referências como os meios de comunicação, a arte e a nossa própria família, em um processo que seguia o ritmo natural da vida (HOMEM, 2019, p. 96). 
Hoje verifica-se que o espaço virtual e a vida paralela criada pelo protagonismo imaginário, ao mesmo tempo que tem o viés positivo de interação, comunicação, dialogicidade, formação de grupos e comunidades com interesses comuns; tem o viés negativo de superexposição, assédio sexual, publicação de informações privadas, exposição a conteúdos inapropriados, cyberbullying entre outros. É necessário dosar o tempo e a forma como nos relacionamos com a tecnologia para que continuemos no controle da situação e não o contrário.

Situar o jovem do nesse mosaico de experiências e vivências que o mundo proporciona, o fazer refletir sobre suas próprias necessidades, seus desejos, sua intuição, seus sonhos enfim trazer para o consciente, externar e planejar seus propósitos, seu projeto de vida, assume papel fundamental na vida escolar para que ele possa atuar de forma independente, empreendedora e crítica na sociedade.

Mas, existe uma única juventude/adolescência? Para Paixão, Almeida e Rosa-Lima (2007), ao pesquisarem as representações sociais dos adolescentes acerca deles mesmos, os resultados indicam a existência de diferentes realidades:

\section{Adolescente}

\section{Características}

\section{Adolescente em Geral Curtidor, feliz, livre, rebelde \\ Adolescente Normal Curtidor, feliz, rebelde, estudante, compromissado, responsável, amigo}

Adolescente Carente

Pobre, responsável, solitário, inteligente, necessitado, órfão, estudante, discriminado

Adolescente Infrator Pobre, irresponsável, solitário, violento, vândalo, triste

\section{Quadro 1 - Representações sociais da adolescência por adolescentes e jovens}

Destaca-se, na categorização apresentada, que o adolescente pode ser visto em duas vertentes: uma na qual ele pode ser livre, rebelde e feliz e outra na qual ele é pobre e solitário. Questiona-se se para essas duas vertentes de adolescentes pensar o projeto de vida tem o mesmo significado.

Dayrell (2007, p. 1108-1109) ao trazer a reflexão acerca da juventude afirma que

Podemos constatar que a vivência da juventude nas camadas populares é dura e difícil: os jovens enfrentam desafios consideráveis. Ao lado da sua condição como jovens, alia-se a da pobreza, numa dupla condição que interfere diretamente na trajetória de vida e nas possibilidades e sentidos que assumem a vivência juvenil. Um grande desafio cotidiano é a garantia da própria sobrevivência, numa tensão constante entre a busca de gratificação imediata e um possível projeto de futuro.

Marcelino, Catão e Lima (2009) nos fornecem pistas para elucidar essa questão ao relatar a pesquisa acerca das representações sociais do projeto de vida entre 
adolescentes do ensino médio. Constatou-se que existem diferenças entre os projetos de alunos de escolas públicas e privadas. Os adolescentes de escola pública associaram o projeto a necessidade de inclusão social e melhoria de vida, sendo a inclusão associada à ascensão social via escolarização. Nessa visão meritocrática "ser alguém" dependerá do esforço pessoal despendido nos estudos. Marcelino, Catão e Lima (2009, p. 552) ressaltam, ainda, que esse "pensamento se ancora no mito da mobilidade social ascendente, alimentado pelo modelo capitalista, em que, tendo-se o mérito individual de lograr êxito, nesse caso academicamente, a ascensão social viria como consequência, quase que automaticamente".

Para os adolescentes da escola privada a preocupação girou em torno das dificuldades de escolha de uma profissão. Pensamento que coaduna com a pesquisa de Paixão, Almeida e Rosa-Lima (2007) quanto ao adolescente "normal". Porém, destaca-se que na pesquisa de Marcelino, Catão e Lima (2009, p. 552) poucos foram os depoimentos que consideravam "o outro" na construção dos projetos de vida. Neste aspecto, os autores ponderam:

Trata-se, pois, de uma construção que se dá entre o "eu" e o "outro", entre o indivíduo e a sociedade, e essa construção não se limita apenas às condições objetivas de vida, mas caracteriza- se na dialética entre a subjetividade e a objetividade, pois é através da reflexão crítica de suas vivências que os indivíduos vêem possibilidade/impossibilidades de superação de uma determinada realidade no futuro (MARCELINO; CATÃO; LIMA, 2009, p. 553)

Em relação ao projeto de vida o adolescente "infrator" se encontra em posição com alto grau de desfavorecimento. Paixão, Almeida e Rosa-Lima (2007) trazem sua condição de pobreza, por si excludente, agravada pela marginalidade. Silveira et al. (2015) realizaram pesquisa com adolescentes na qual investigaram os projetos futuros de adolescentes privados de liberdade para cumprimento de medida socioeducativa.

Os adolescentes investigados apresentaram projetos futuros diferenciados, os quais envolveram aspectos positivos (família, trabalho, estudo e aquisição de bens materiais), negativos (vingança) e de indefinição. Adolescentes com projetos futuros positivos precisam ser incentivados e receber suporte para a efetivação desses planos, enquanto adolescentes com projetos indefinidos ou negativos necessitam de atenção para superar essa condição e elaborar projetos positivos (SILVEIRA et al. 2015, p.52).

Porém, não se pode deixar de destacar que a pobreza não é condição sine qua non para a violência e adolescentes de outros "estratos sócio-econômicos mais elevados também cometem infrações graves” (PAIXAO; ALMEIDA; ROSA-LIMA, 2012, p. 290).

Portanto, "são evidentes as diferenças entre os grupos das diferentes classes sociais devido a diferentes formas de inserção social. Mas nada disso está apresentado e debatido, pois a adolescência está tomada como universal e natural" (BOCK, 2007, p. 73). 
Ressalta-se que para trabalhar com o projeto de vida no contexto escolar é preciso considerar essa diversidade de contexto da juventude. Então o primeiro passo é conhecer os estudantes social, cultural e afetivamente, levando em conta as origens, contexto, a história de vida. Considerar que ao chegar ao ensino médio ele possui experiências e vivências consideráveis que influenciam seu comportamento, condutas, preferências etc. (DAYRELL; CARRANO, 2014).

A escola como espaço social de construção e formação de identidade dos adolescentes configura-se como importante meio de viabilização de seus projetos de vida, especialmente no ensino médio, período em que se sentem a pressão dos pais e começam a posicionar-se profissional, social e financeiramente. Arantes e Klein (2016) consideram

O sentido atribuído à escolarização, geralmente, remete os sujeitos ao futuro. Ainda que projetos se orientem para o futuro, eles são pensados e formulados no tempo presente, tendo por base experiências e oportunidades vividas e significadas no tempo presente (p. 140).

A escola como palco de experiências, efervescência cultural na qual os adolescentes expressam gostos, comportamentos, estilos é um ambiente rico para promover a solidez, planificação e orientação de um projeto de vida já que sua formação aponta para o futuro.

Conquanto, quando se pensa em projeto de vida surge vários questionamentos: 0 que quero ser? Qual área seguir? Que profissão vou escolher? Quanto irei ganhar? Essas indagações baseiam-se na projeção do senso comum que o projeto de vida se restringe apenas a questão profissional. No entanto, o projeto de vida é mais amplo, possui vertentes diversas que contemplam todas as áreas da vida do sujeito. Ortega y Gasset (1983) falam em dois elementos essenciais para a construção do projeto de vida: as circunstâncias e a vocação.

O primeiro abre espaço para a liberdade de escolha individual; já o segundo traz a opção pessoal de segui-la ou não. A circunstância é dada, mas abre-se em um leque de possibilidades à liberdade de escolha de cada indivíduo, e a opção recai sobre aquela que se relaciona ao seu projeto. Este, por sua vez, é imaginado em vista de suas circunstâncias que se inserem em um contexto sócio histórico e pessoal (p. 71).

Damon (2008) desenvolveu um conceito para o projeto de vida - purpose ou projeto vital. Para o pesquisador, projeto vital é uma intenção que vai além de objetivos e metas estabelecidas individualmente, envolve o propósito de alcançar algo que é significativo também para o mundo. Os projetos vitais são construídos com base em valores morais expressando um engajamento do sujeito em fazer a diferença no mundo, a partir de suas potencialidades e interesses, em uma postura otimista, ativa, persistente e empreendedora. Destacam-se alguns pontos principais nos projetos vitais: 
1. Amplitude e estabilidade: projetos vitais podem ser entendidos como uma espécie de meta, porém são mais estáveis e têm um alcance amplo, ao passo que as metas são mais pontuais e imediatas.

2. Significado pessoal e autotranscendente - projetos vitais têm um significado pessoal, mas também têm um componente externo, que se traduz no desejo de fazer a diferença no mundo, de contribuir para assuntos que transcendem os interesses autocentrados.

3. Algo a ser realizado - projetos vitais não se orientam para um fim definido, dirigem-se sempre a uma realização, a uma forma de orientação a ser seguida no curso da vida. Essa orientação pode ser material ou não material, externa ou interna, perceptível ou não, mas trata-se de uma característica necessária, não em sua concretude, mas em seu senso de direção (DAMON; MENON; BRONK, 2003).

\section{Legislação educacional e Projeto de vida}

Formar o ser humano implica na consideração de seus projetos pessoais. 0 espaço escolar, como instituição inserida no contexto sócio-histórico-cultural em que os jovens estão presentes, deve possibilitar a reflexão sobre os valores, as escolhas e a identidade de cada jovem estudante.

Para tanto, precisa-se analisar o que as políticas públicas brasileiras vêm desenhando para a juventude atual e como vem emergindo o tema "Projeto de vida" nessas políticas. Inteirar-se desse aspecto é verificar o que pode ser concretizado. Apesar dos avanços legais na esfera da garantia de direitos para jovens e da criação de instituições governamentais para o desenvolvimento de políticas a eles destinadas, é preciso reconhecer que ainda há muito a se fazer no campo das políticas públicas voltadas a esse segmento.

De toda forma, o Brasil já possui legislação protetiva para jovens. Dentre elas, a Lei 12.852/13 que institui o Estatuto da Juventude. Em 2010 foi aprovada a Proposta de Emenda Constitucional no 65, conhecida como PEC da Juventude, após tramitar sete anos no Congresso Nacional.

Em relação ao Projeto de vida, a Lei Federal 13.415, de 2017, prevê que "os currículos do ensino médio deverão considerar a formação integral do estudante, de maneira a adotar um trabalho voltado para a construção de seu projeto de vida e para sua formação nos aspectos físicos, cognitivos e socioemocionais" (BRASIL, 2017a, Art. 3., $\S 7^{\circ}$, grifo do autor).

Essa lei, conhecida como a lei da reforma do ensino médio brasileiro, propõe mudanças no currículo, na estrutura, na jornada, com a criação dos itinerários formativos, ou seja, implementa uma série de modificações, porém sem o devido respaldo estrutural.

Essas mudanças acarretaram alterações na Lei de Diretrizes e Bases da Educação Nacional (LDB 9494/1996) e são obrigatórios a todas as escolas. Vale ressaltar que o 
instrumento foi elaborado sem a participação da população, educadores, especialistas, pesquisadores, professores, estudantes, ou seja, a parcela diretamente ligada a área educativa.

Pesquisadores apontam aspectos negativos à reforma, entre eles o fato da perpetuação da divisão entre o ensino técnico e propedêutico, já que os estudantes terão que optar por itinerários formativos específicos. Além disso, devido à dissolução de componentes curriculares, aumento da carga horária discente na escola sem a reestruturação da infraestrutura escolar ou formação de professores específica a reforma trouxe as escolas brasileiras a necessidade de buscar alternativas pedagógicas para trabalhar o Projeto de vida.

A Base Nacional Comum Curricular (BNCC) do ensino médio, homologada em 2018, é o documento normatizador e regulamentador das alterações provenientes Lei Federal 13.415/2017. A BNCC é um documento de caráter normativo que define as aprendizagens essenciais e competências gerais da educação básica e traz o projeto de vida na sexta competência, ampliando-o para o mundo do trabalho e reiterando o foco no protagonismo discente e no seu projeto de vida.

Valorizar a diversidade de saberes e vivências culturais e apropriar-se
de conhecimentos e experiências que lhe possibilitem entender as
relações próprias do mundo do trabalho e fazer escolhas alinhadas ao
exercício da cidadania e ao seu projeto de vida, com liberdade,
autonomia, consciência crítica e responsabilidade (BRASIL, 2017b, p. 9,
grifo do autor).

Como o projeto de vida é citado nas competências gerais, infere-se que deve estar presente nas três etapas da educação básica - educação infantil, ensino fundamental e ensino médio. No entanto, a obrigatoriedade nos currículos escolares privilegiou o ensino médio.

Em função dessa legislação e tendo em vista a solicitação das escolas de uma referência que pudesse subsidiar o trabalho docente, a Coordenação Geral de Ensino Médio, do Ministério da Educação (Mec) encaminhou às Secretarias Estaduais de Educação documentos referentes ao Novo Ensino Médio, dentre eles destaca-se a Orientação pedagógica para trabalho com Projeto de Vida ${ }^{3}$ como componente curricular, documento norteador para o trabalho com Projeto de Vida.

Este estudo extrapola a imposição legal e dá ênfase a preocupação de como as escolas poderão desenvolver o trabalho pedagógico para que o projeto de vida não priorize aspectos valorizados pelo status quo, modismos, carreiras profissionais minimizando as capacidades e sonhos dos jovens.

\section{Método}

\footnotetext{
${ }^{3} \mathrm{O}$ documento não está disponível na internet. Circulou internamente nas secretarias estaduais de educação. Rev. Nova Paideia - Revista Interdisciplinar em Educação e Pesquisa Brasília/DF, v. 2, n. 1. p. 19 - 34 - ANO 2020 ISSN 2674-5976 DOI: $10.36732 /$ riep.v2i1.52
} 
Este trabalho tem como objetivo analisar inserção da temática Projeto de vida como componente curricular obrigatório na Base Nacional Comum Curricular (BNCC) do Ensino Médio a partir de fontes secundárias, caracterizando-se como uma pesquisa bibliográfica.

Para Chiara et al. (2008)

A pesquisa bibliográfica é feita com o intuito de levantar um conhecimento disponível sobre teorias, a fim de analisar, produzir ou explicar um objeto sendo investigado. A pesquisa bibliográfica visa então analisar as principais teorias de um tema $(\mathrm{s} / \mathrm{p})$.

Consistiu inicialmente numa busca realizada em bases de dados, em especial Scielo e Redalyc, utilizando-se como filtro as palavras-chave: projeto de vida, juventude e ensino médio. Os artigos que apresentaram ao menos duas palavras-chave no título foram selecionados. Em seguida foi realizada a leitura dos resumos e descartados os trabalhos que continham outros subtemas, tais como: gravidez na adolescência, estudos de caso, violência, entre outros. Por fim, chegou-se a 22 artigos a serem lidos e analisados.

\section{Resultados e discussão}

Optou-se aqui por apresentar uma possibilidade de efetivação da proposta apresentada pelo documento Orientação pedagógica para trabalho com Projeto de Vida como componente curricular. 0 documento traz linhas gerais para que cada escola possa elaborar sua proposta pedagógica, conforme sua realidade.

Destaca-se o fato de que o trabalho com projeto de vida "não deve ser confundido com escolha profissional, tampouco está desatrelado ao mundo produtivo, uma vez que auxilia o jovem a se conhecer, entender sua relação com o mundo e desenhar o que espera para si no futuro" (PEREIRA; TRANJAN, s/d). 0 documento apresenta ainda:

O Projeto de Vida não é apenas escolha profissional, tampouco está dissociada do mundo produtivo, pois contribui para 0 autoconhecimento, para a capacidade de situar-se no mundo e reconhecer as possibilidades e para o desenvolvimento de valores e habilidades que contribuam para que o estudante faça boas escolhas ao longo da sua trajetória. Elenca-se quatro macrotemas ou eixos para a organização do componente curricular de Projeto de Vida: Autoconhecimento; Eu x Outro; Planejamento e; Preparação para o mundo fora da escola (PEREIRA; TRANJAN, s/d. grifo nosso).

Gontijo (2020) ao investigar a permanência e êxito como forma de inclusão dos estudantes apresenta um modelo para elaboração de intervenções pedagógicas sendo o trabalho com o Projeto de vida uma dessas possibilidades. 
A autora defende que o Projeto de vida é um tema que pode promover a inclusão em função das habilidades desenvolvidas quanto ao autoconhecimento, eu x outro e planejamento e que as atividades pedagógicas propostas devem seguir a metodologia da aprendizagem dialógica, a saber: igualdade de diferenças, dimensão instrumental, solidariedade, criação de sentido, transformação, inteligência cultural, diálogo igualitário e participação.

Para Aubert et. al. (2008) a igualdade de diferenças pressupõe respeitar a todos independente de suas diferenças é uma premissa que deve prevalecer uma vez que o projeto vai abranger um público variado de discentes. A dimensão instrumental caracteriza-se pelo diálogo, a reflexão, os conteúdos e habilidades escolares são instrumentos a serem incluídos na vida social. A competitividade deve dar lugar a solidariedade e envolver todos nesse sentimento para que participação seja alcançada. A criação de sentido não poderá ser esquecida para que a motivação seja mantida no decorrer do processo e o mundo atuante entre professor e estudante possa dialogar de forma simbiótica. A transformação é a ferramenta para mudar a realidade envolta, tornando-se um agente transformador da sociedade. A inteligência cultural será buscada pelo saber acadêmico que cada um possui atrelado a sua cultura criando uma consciência crítica e transformadora. No diálogo igualitário todos tem igual oportunidade de falar, se expressar, expor seus argumentos, sem utilizar de hierarquia ou qualquer forma de preterição.

Gontijo (2020) trata ainda das competências socioemocionais, pois o fomento delas auxilia no processo de entendimento e manejo das emoções fornecendo ao estudante ferramentas para lidar com seu emocional.

Nesse sentido, a proposta pedagógica com o Projeto de vida deve procurar

[...] explorar a ideia de o adolescente como ser ativo e participativo, capaz de atuar no mundo profissional, projetar-se na construção de seu futuro e da sociedade em si, valorizando os laços afetivos e sua preocupação com o outro. Neste sentido, o seu projeto de vida é um elemento essencial na construção da personalidade moral (D'AUREA TARDELI, 2006. p. 1).

No caso específico do Ensino Médio, Pereira e Tranjan (s/d) apresentam as habilidades a serem desenvolvidas no trabalho com projeto de vida, por ano: 

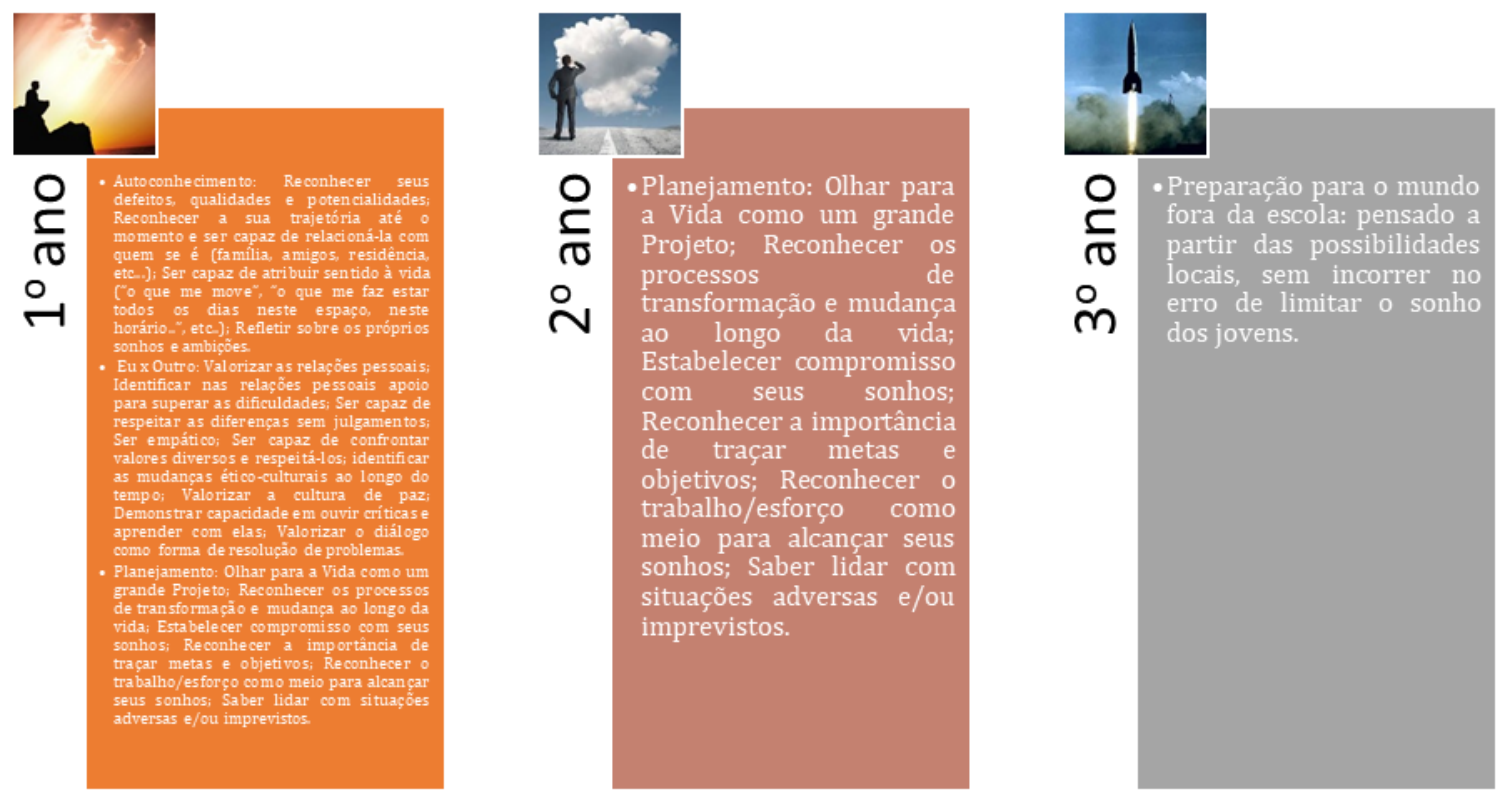

Figura 2 - Organização de habilidade por ano, no Projeto de vida

Autoconhecimento: Para realizar um projeto de vida é necessário autoconhecimento; sua ausência implica divagar, fantasiar entre projetos mirabolantes e supérfluos beirando modismos ou urgências econômicas, sociais ou financeiras. Firmar a personalidade, a moral, os valores que traz consigo, ou seja, sua bagagem de vida gerando autoconhecimento, pontos fortes, preferências, gostos, faz com que o projeto de vida criado seja singular, único e intransferível; o que contribui para trilhar um futuro mais sólido e construtivo.

Eu x outro: Vivemos em uma sociedade cada vez mais dependente de comunicação e tecnologia. Apesar do mundo virtual afastar as pessoas fisicamente, a interação e comunicação entre elas é intensa, repleta de significados, expectativas, intenções. Não vivemos ilhados, precisamos estar em constante troca com o outro e o projeto de vida não pode deixar isso de lado. Ser solidário, empático, conseguir identificar as necessidades das outras pessoas nos faz crescer pessoalmente e espiritualmente. Respeitar a diversidade de personalidades, estilos, formas de ser e viver diante do mundo cada vez mais eclético faz parte do nosso ser social, contribui para o crescimento interior e nos faz repensar e refletir sobre nossos ideais a todo instante. Conhecer o outro é o próximo passo para entender o contexto em que se vive, analisando, avaliando, recriando e projetando expectativas para um projeto de vida além de si mesmo, que tenha compromisso para além do eu conectando-se com a comunidade, a sociedade e o mundo.

Planejamento: Crucial para a organização do projeto de vida. Planejar é colocar em ação os sonhos, metas e objetivos a serem alcançados. 0 projeto de vida envolve diversas áreas da nossa vida - profissional, financeira, saúde física e emocional, autoconhecimento e relações interpessoais que devem ser planejamentos a longo prazo; sendo assim esquematizar, estipular prazos e ter um fio condutor que rege nossos sonhos contribui para o êxito no projeto de vida. 
Preparação para o mundo fora da escola: 0 projeto de vida nunca termina, ele vai além da sala de aula, da escola é para toda a vida. Os jovens se inserem em um contexto mais amplo da comunidade e podem desenvolver valores essenciais ao processo de decisão sobre seu futuro, conservando sua singularidade em um projeto coletivo. Aqui a educação integral consolida-se como possibilidade de desenvolvimento pessoal e social. 0 aluno deve refletir sobre seu processo de aprendizagem na escola associado aos caminhos para construção do seu projeto de vida, em que medida as atividades realizadas dentro da escola irão contribuir para consecução do seu projeto. Perceber a relação de causa e consequência entre as ações realizadas no passado, como elas interferem no presente e como poderão interferir no futuro.

Assim, o documento Orientação pedagógica para trabalho com Projeto de Vida como componente curricular contém elementos para o desenvolvimento do trabalho pedagógico durante os três anos do ensino médio. Porém, infere-se que o fato de, no $1^{\text {o }}$ ano serem exploradas três temáticas, é possível uma sobrecarga de atividades e a relação tempo/espaço não favorecer o cumprimento dessa demanda.

Ressalta-se que as habilidades são progressivamente desenvolvidas, pois subentende-se que são alcançadas a longo prazo e de forma contínua. Neste caso, indicase repensar a dimensão curricular da proposta do documento.

Levando em consideração as categorias de adolescentes apresentadas por Paixão, Almeida e Rosa-Lima (2012) as habilidades serão manifestadas de formas diferentes, no entanto, o intuito será sempre o autoconhecimento, o planejamento e demais habilidades elencadas elaborando desse modo um projeto de vida efetivo.

O projeto de vida compreendido pela BNCC tem potencial transversal cabendo sua contextualização com os demais componentes curriculares. É preciso superar as formas de fragmentação do processo pedagógico em que os conteúdos não se relacionam, não se integram e não se interagem (BRASIL, 2019, s/p). A articulação com as áreas do conhecimento pode mostrar a relevância dessa temática para a formação do cidadão, uma vez que atende as demandas da sociedade contemporânea e faz parte da realidade do estudante.

Na prática, a implantação do projeto de vida na escola enfrentará grandes desafios. Pensar na flexibilização dos currículos, adequar a carga horária e sua interação com os demais componentes curriculares exigirá habilidade do professor. Portanto, é necessário pensar a formação do professor para saber lidar com essa multiplicidade, portanto, cursos específicos de formação continuada, oficinas pedagógicas, cursos a distância são meios de desenvolver habilidades docentes para o trabalho com Projeto de vida.

A transversalidade orienta para a necessidade de se instituir, na prática educativa, uma analogia entre aprender conhecimentos teoricamente sistematizados (aprender sobre a realidade) e as questões da vida real (aprender na realidade e da realidade). Numa compreensão interdisciplinar do conhecimento, a transversalidade tem significado, sendo uma proposta didática que possibilita o tratamento dos conhecimentos escolares de forma integrada. Assim, a gestão do conhecimento parte do 
pressuposto de que os sujeitos são agentes da arte de problematizar e interrogar, e buscam procedimentos interdisciplinares capazes de acender a chama do diálogo entre diferentes sujeitos, ciências, saberes e temas (BRASIL, 2010, p. 24).

\section{Conclusões}

Apesar de autores considerarem complexo o jovem traçar um projeto de vida devido as inúmeras possibilidades que o mundo pós-moderno apresenta e a necessidade de fazer escolhas diante dessa multiplicidade é fundamental desenvolver este tema na escola, pois ela é o lugar onde o educar e aprender são fenômenos que devem envolver todas as dimensões do ser humano.

A intervenção pedagógica objetiva promover situações que levem jovem a pensar em que medida as atividades realizadas, tanto na escola como fora dela, estão associadas às escolhas e decisões referentes ao planejamento e à definição de seu Projeto de Vida que não se resume a escolha profissional, mas deve levar em conta várias vertentes ampliando-se às múltiplas dimensões do estudante.

As etapas autoconhecimento, a relação com o outro e com a sociedade, o planejamento e a preparação para o mundo do trabalho devem ser gradativamente alcançados ao longo dos três anos do ensino médio quando se pensa num projeto de vida exitoso. Para isso os princípios da aprendizagem dialógica devem ser seguidos.

0 projeto de vida é traçado entre o ser e o querer ser, é refletir no presente para projetar o futuro com ações concretas. Neste trajeto, o projeto não poderá ser individualizado; precisa estar integrado as pessoas, aos familiares, a um universo social e profissional que vai além das aspirações próprias, envolve um modo de estar no mundo e nele fazer a diferença. 0 Projeto de Vida nunca termina, ele vai além da sala de aula e da escola e é para toda a vida.

Implantar o projeto de vida na escola é tarefa complexa que demanda planejamento, formação docente, infraestrutura, entre outros aspectos. É adentrar os sonhos, expectativas, ideais dos jovens. É fundamental que a instituição escolar - seus professores e os gestores - busquem conhecer sobre a realidade dos estudantes de forma a interagir e colaborar na construção de seus projetos de vida. 0 desafio está posto. 


\section{Referências}

ARANTES, V. A.; KLEIN, A. M. Projetos de vida de jovens estudantes do ensino médio e a escola. Educação \& Realidade, Porto Alegre, v. 41, n. 1, p. 135-154, jan./mar. 2016.

AUBERT, A. et al. Aprendizaje dialógico en la sociedad de la información. Barcelona: Hipatia, 2008 In: Comunidade de aprendizagem - aprendizagem dialógica. Disponível em:

<https://www.comunidadedeaprendizagem.com/uploads/materials/3/bbea4bd30043 29144 308d8efcc1c8061.pdf> Acesso em: 17 jul 2019.

BOCK, Ana Mercês Bahia. Adolescência como construção social: estudo sobre livros destinados a pais e educadores. Revista Semestral da Associação Brasileira de Psicologia Escolar e Educacional (ABRAPEE), Vol. 11, n. 1. Jan./Jun. 2007, p. 63-76. Disponível em: <http://www.scielo.br/scielo.php?script=sci_arttext\&pid=S141385572007000100007> Acesso em: 22 mar 2020.

BRASIL. Base Nacional Comum Curricular - BNCC. Ensino Médio. MEC/CNE, 2017a. Disponível em:

<http://portal.mec.gov.br/index.php?option=com_docman\&view=download\&alias=796 1 1-anexo-texto-bncc-aprovado-em-15-12-17-pdf\&category_slug=dezembro2017pdf\&Itemid=30192> Acesso em: 21 set 2019

Base Nacional Comum Curricular - BNCC. Temas contemporâneos transversais na BNCC. MEC, 2019. Disponível em:

$<\mathrm{http}$ //basenacionalcomum.mec.gov.br/images/implementacao/contextualizacao_temas_cont emporaneos.pdf $>$ Acesso em: 24 mar 2020.

. Lei Federal no 13.415, de 16 de fevereiro de 2017. Altera as Leis $\mathrm{n}$ o 9.394, de 20 de dezembro de 1996, que estabelece as diretrizes e bases da educação nacional. 2017b. Disponível em:

<http://www.planalto.gov.br/ccivil_03/_Ato20152018/2017/Lei/L13415.htm> Acesso em: 02 mar 2020.

. CNE/CEB (Conselho Nacional de Educação/Câmara de Educação Básica). Parecer No 11, de 7 de outubro de 2010. Diretrizes Curriculares Nacionais para o Ensino Fundamental de 9 (nove) anos. Diário Oficial da União, Brasília, 9 de dezembro de 2010, seção 1, p. 28.

CHIARA, I. D. et al. Normas de documentação aplicadas à área de Saúde. Rio de Janeiro: Editora E-papers, 2008.

DAMON, W. 0 que o Jovem quer da Vida? Como pais e professores podem orientar e motivar os adolescentes. São Paulo: Summus, 2008.

DAMON, W.; MENON, J. BRONK, K. The Development of Pur- pose During Adolescence. Applied Developmental Science [online], v. 7, n. 3, p. 119-128, out. 2003. 
DAYRELL, J. A escola "faz" juventudes? Reflexões em torno da socialização juvenil. Educ. Soc. , Campinas, vol. 28, n. 100 - Especial, p. 1105-1128, 2007. Disponível em:<http://www.cedes.unicamp.br> Acesso em: 22 mar 2020.

. O jovem como sujeito social. Revista Brasileira de Educação. no 24. UFMG, 2003. Disponível em: <http://www.scielo.br/pdf/rbedu/n24/n24a04.pdf> Acesso em: 10 nov. 2019.

DAYRELL, J.; CARRANO, P. Juventude e ensino médio: quem é este aluno que chega à escola. In: DAYRELL, J.; CARRANO, P.; MAIA, C. L. (org.) Juventude e ensino médio: sujeitos e currículos em diálogo. Belo Horizonte: Editora UFMG, 2014.

D’AUREA-TARDELI, D. A manifestação da solidariedade em adolescentes: um estudo sobre a personalidade moral. Tese de doutorado. Instituto de Psicologia da Universidade de São Paulo. São Paulo, 2006.

GONTIJO, S.B.F. Permanência e êxito na escola: estratégias pedagógicas. No prelo, 2020.

HOMEM, Maria. Posto, logo existo? Revista GOL, n. 212, nov. 2019.

MANNHEIM, K. O Problema da Juventude na Sociedade Moderna. In: BRITO, Sidney. (Org.). Sociologia da Juventude I: da Europa de Marx à América Latina de hoje. Rio de Janeiro: Zahar Editores, 1968. P. 69-94

MARCELINO, M. Q. dos S.; CATAO, M. de F. F. M.; LIMA, C. M. P. de. Representações sociais do projeto de vida entre adolescentes no ensino médio. Psicol. cienc. prof., Brasília, v. 29, n. 3, p. 544-557, 2009. Disponível em:

<http://www.scielo.br/scielo.php?script=sci_arttext\&pid=S1414-

98932009000300009\&lng=en\&nrm=iso>. Acesso em: 06 Mai, 2020.

ORTEGA y GASSET, J. La Rebelión de las Masas. Madrid: Revista de Occidente, Alianza Editorial, 1983.

PAIXÂO, D. L. L.; ALMEIDA, A. M. de O.; ROSA- LIMA, F. Representações sociais da adolescência por adolescentes e jovens. Psicologia e Saber Social, 1(2), 278-294, 2012.

PEREIRA, W. J.; TRANJAN, P. Orientação Pedagogica para trabalho com projeto de vida enquanto componente curricular. Coordenação de ensino médio em tempo integral, MEC.

SILVA, C. R.; LOPES, R. E. Adolescência e juventude: entre conceitos e políticas públicas. UFSCar, São Carlos, Jul-Dez 2009, v. 17, n.2, p 87-106.

SILVEIRA, K. S. da S. et al. Projetos futuros de adolescentes privados de liberdade: implicações para o processo socioeducativo. Revista Psicologia: Teoria e Prática, 17(2), 52-63. São Paulo, SP, maio-ago. 2015. ISSN 1516-3687 (impresso), ISSN 1980-6906 (online).

Rev. Nova Paideia - Revista Interdisciplinar em Educação e Pesquisa Brasília/DF, v. 2, n. 1. p. 19 - 34 - ANO 2020 ISSN 2674-5976

DOI: $10.36732 /$ riep.v2i1.52 
